\title{
Inner strategies of coping with operational work amongst SAPS officers
}

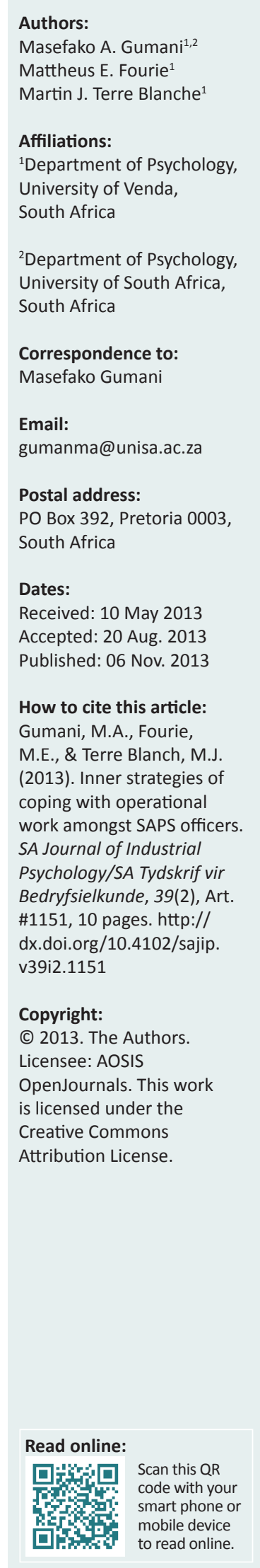

Orientation: Identification of the inner coping strategies used by South African Police Service (SAPS) officers who do operational work is something the SAPS should consider to ensure the officers' management of trauma and efficiency at work.

Research purpose: The objective of this study was to describe inner coping strategies used by officers in the Vhembe district (South Africa) to reconstruct stressful and traumatic experiences at work.

Motivation for the study: Most studies on coping amongst SAPS officers focus on organisational stress and not on the impact of the officers' operational work.

Research design, approach and method: An exploratory design was used and 20 SAPS officers were selected through purposive sampling. In-depth face-to-face and telephone interviews, as well as diaries were used to collect data, which were analysed using content thematic data analysis.

Main findings: The results showed that the main categories of coping strategies that led to management of the impact of operational work amongst the selected sample were centred around problem-focused and emotion-focused strategies, with some use of reappraisal and minimal use of avoidance. Considering the context of the officers' work, the list of dimensions of inner coping strategies amongst SAPS officers should be extended.

Practical/managerial implications: Intervention programmes designed for the SAPS, including critical incident stress debriefing, should take the operational officers' inner strategies into account to improve the management of the impact of their work.

Contribution/value-add: This study contributes to the body of knowledge on the inner coping strategies amongst SAPS officers, with special reference to operational work in a specific setting.

\section{Introduction \\ Problem statement}

The work environment for South African Police Service (SAPS) officers is generally considered violent (Pienaar, Rothmann \& Van de Vijver, 2007). Consequently, much research on these officers has been focused on ill-health concepts such as stress, burnout and trauma (Minnaar \& Mistry, 2006; Pienaar \& Rothmann, 2003), rather than on how they reconstruct those negative experiences at work.

Positive psychology, amongst others, looks at how quality of work life can be determined by positive work experiences (Rani \& Kumar, 2012), but only a few researchers have investigated how SAPS officers are able to continue doing their work (Louw \& Viviers, 2010; Rothmann, Jorgensen \& Hill, 2011; Storm \& Rothmann, 2003). Despite positive psychology's emphasis on what makes workers thrive at work, current focus is still on how the officers' work disadvantages them rather than on how it develops them. The main concepts that contribute towards this field's positive tone, such as workers' positive mood, work-related flow, work engagement and job satisfaction (Bakker \& Daniels, 2012), are rarely looked at in the SAPS. These findings show that the SAPS officers' commitment to work, specifically considering the operational effects of their work, is worth researching.

Few studies that raised the need to shift focus from negative organisational effects to positive experiences at work include research on how SAPS officers manage to cope with the nature of their work (Madu \& Poodhun, 2006; Pienaar \& Rothmann, 2003). Thus, much research is still required in this regard. It appears that much of the research on coping amongst SAPS officers focuses on the organisational context rather than on the specific ways that officers cope with the effects of their operational work. 
For instance, Pienaar and Rothmann (2003) conducted a study on the coping strategies used by police officers in eight provinces in South Africa. The study focused on stress caused by the officers' experiences of the organisational context of their workplaces. Madu and Poodhun (2006) concentrated on officers' coping strategies to deal with organisational factors, such as salaries, the number of working hours and working relationships with superiors, amongst others, that led to high levels of stress amongst the officers.

Pienaar et al. (2007) looked at whether or not suicide ideation amongst SAPS officers could be predicted by occupational stress, personality traits and coping strategies. Storm and Rothmann (2003) conducted a study focusing on officers' organisational stressors that resulted in burnout. Louw and Viviers (2010) investigated how Moos's hypothesised stress and coping model fitted a general sample of officers within the SAPS. Focus was also on burnout rather than vicarious traumatisation (VT), which is common amongst those who do operational work. Rothmann et al. (2011) studied the relationship between coping strategies and work engagement amongst SAPS officers. Again, focus was not specifically on officers who do operational work.

It was, therefore, the current study's objective to describe the inner coping strategies used by operational work officers within their context in the Vhembe district, Limpopo, to reconstruct their stressful and traumatic experiences when they help primary victims of trauma.

\section{Literature review Implications of the use of inner coping strategies}

Even though workplace programmes have been established to deal with VT amongst the police, literature shows the importance of using personal strategies to both identify and deal with this type of trauma. This is more important when stress management programmes cannot be equally applicable to individual police officers (Minnaar \& Mistry, 2006), when police officers are not aware of such workplace programmes (Kgalema, 2002), as well as due to the stigma attached to debriefing (Jonas, 2003). Maladaptation tends to result if the programmes adopted by employers do not work (Kgalema, 2002). Generally, informal coping strategies tend to be opted for by police officers (Wright, Powell \& Ridge, 2006). Caution is also given to not replace self-care amongst police officers with peer support, due to the shortcomings of peer support (Bell, Kulkarni \& Dalton, 2003). This calls for the use of personal ways of coping in order to do the work satisfactorily (Kgalema, 2002).

Effective coping when applied to police stress refers to executing particular behaviour to face the situations encountered rather than avoiding them, and to confidently manage the way in which one responds to such situations emotionally (Pienaar et al., 2007). The choice and degree of use of coping strategies also differ from one individual to another on the basis of their perceived usefulness and effectiveness (Louw \& Viviers, 2010). Nevertheless, their common success is determined by serving a mediatory role of reducing stress (Beasley, Thompson \& Davidson, 2003). The strategies should achieve the goals that the individuals set for themselves and also enhance the efficiency with which they do their work (Storm \& Rothmann, 2003). This leads to psychological growth and the development of new and effective coping strategies for future use (Waters \& Ussery, 2007).

The process of coping requires looking into the issue of comprehensiveness (Latack \& Havlovic, 1992), that is, concentrating on the focus of coping (the stressful situation that coping is directed at and the emotional reactions shown) and the method of coping (the strategy that is used to deal with the situation). A distinction is made amongst the following methods of coping: cognitive (perception, thinking, planning and organising how to deal with stress), behavioural (being actively involved in executing some action to deal with the situation), proactive (being in charge of the situation and acting proactively to handle it accordingly), escape (trying not to be involved with the stressor by avoiding it), social (involvement of help from other people) and solitary (dealing with the situation alone).

\section{Theories of coping in the workplace}

The conservation of resources (COR) theory holds the presupposition that individuals focus on obtaining, developing, retaining and protecting resources of coping in life, when situations pose a threat to the resources, when the resources are lost or when they do not provide good returns (Hobfoll, Dunahoo \& Monnier, 1995). Even though personal growth is considered, this theory provides a general approach to the issue of coping by focusing on general situations rather than on specific contexts, such as work.

Despite this shortcoming, the principles of the COR theory together with the salutogenic paradigm may be helpful as they emphasise individual discovery of the meaning of trauma that is derived from the encountered critical incidents; maintaining personal resources to deal with the trauma; and exploring the effectiveness of such coping resources. The salutogenic paradigm also emphasises six constructs: sense of coherence, locus of control, self-efficacy, hardiness, potency and learned resourcefulness (Bekwa \& De Beer, 2009). These are vital in ensuring management of trauma at work.

The job demands-resources (JD-R) model acknowledges that every type of profession comes with distinct demands that may lead to stress and thus requires specific resources to deal with the stress. The objectives of using these resources are helping an individual to achieve the goals set at work, reducing the demands and costs of a job and promoting personal growth, learning and development (Bakker \& Demerouti, 2006). Due to its recognition of the fact that different professionals cannot be expected to use the same resources to handle their job demands, the JD-R model takes into account the dynamic and specific demands faced in those specific jobs and, therefore, the nature of the resources 
required. This strength coincides with the objective of this study, which is to recognise the fact that the context in which the SAPS officers in the Vhembe district work imposes specific job demands and thus calls for adoption of particular resources to handle those demands.

The demand-control model also adds value to understanding coping with the demands of the work environment. Its basic premise is having a sense of control over one's work, as the degree of control exercised contributes significantly to one's health. It sees the work environment as being constructed by man and therefore can be changed so as to enhance active learning. Therefore, the ideal work environment is one that comprises manageable demands and high control. This is an environment in which a worker has the autonomy to determine how and when to deal with challenges faced. This implies active behaviour in workers, learning new things, handling challenges, having a sense of mastery over the work and self-efficacy (De Jonge, Dollard, Dormann, Le Blanc \& Houtman, 2000).

Aspects of these theories are applicable to understanding how possible it is to reconstruct work experiences that are otherwise considered stressful or traumatic. The current study may also make a contribution in this regard.

\section{Research design \\ Research approach and strategy}

A qualitative research approach was adopted to give indepth descriptions of participants' lived experiences about coping with their operational work (Barbour, 2001). An exploratory research design (Neuman, 2007) was used to explore the inner strategies of coping used by SAPS officers and to describe the effectiveness of those strategies from the officers' perspective.

\section{Research method}

\section{Research setting}

The study was conducted in the Vhembe district, in the northernmost part of the Limpopo province of South Africa. The district is largely rural with the majority of people speaking Tshivenda and has more female than male residents (Department of Cooperative Governance and Traditional Affairs, 2011). Police stations are located at the entry points of major villages in this district.

\section{Entree and establishing researcher roles}

The primary researcher received ethical clearance to conduct the study from the ethics committee at the Department of Psychology, University of South Africa, South Africa. The Provincial Commissioner of Police in Limpopo was also requested for permission to conduct the study, which was then given to station commissioners in the different police stations. The role of the primary researcher as a doctoral student was made clear to those who provided authorisation for conducting the study.

\section{Selection of participants}

Purposive sampling was used to select participants in the family violence, child abuse and sexual offences (FCS), domestic violence, field training, detective and social crime prevention units who knew about and had experience with coping with operational work (Franchuk, 2004). These were officers working with domestic violence, murder, rape and road accident cases. Data were collected from a sample of 20 police officers from the Thohoyandou, Siloam, Vuwani, Levubu, Mutale, Tshaulu and Makuya policing areas in the Vhembe district. This number was considered on the basis of meeting data saturation (Strauss \& Corbin, 1998). The final sample had the following characteristics: 19 Tshivendaspeaking and one Xitsonga-speaking officers; male and female participants; participants occupying the ranks of constable, sergeant, inspector, captain and superintendent; participants with seven months to 24 years experience working in a unit; both single and married participants; participants affiliated to the Christian religion; levels of education that varied from Grade 10 to a university degree; and an age range of 27-55 years.

\section{Data collection methods}

Unstructured and open-ended interviews were used for the purpose of gathering data (Strauss \& Corbin, 1998). The initial interview question was phrased so as to gather data on the participants' situational experiences of critical incidents during their work and how they coped with the impact of these. The question was: 'Tell me about a typical day in your life as a police officer'. This was followed by questions on the officers' operational experiences and coping strategies used. Follow-up telephone interviews were also conducted to clarify data that were gathered, and also to check for correctness, new information and representativeness of the data (Leedy, 1997). Participants were further requested to keep diaries and make weekly entries of their operational work experiences and coping (Franchuk, 2004).

\section{Recording of data}

A digital voice recorder was used to record the responses of the participants and ensure repeated re-visitation of the data during data analysis. Field notes were also taken during the initial interviews to record vital information and to help with follow-up questions.

\section{Data analysis}

The content thematic data analysis method was used to analyse data and the following phases from Joffe and Yardley (2004) were used:

- Coding:

- Sentences were used as the unit of coding. Manifest and latent themes were coded. Patterns in the data were noted and labelled with codes.

- Data were divided into a set of categories, showing code names, description of each code and examples of quotes from text, thus creating a coding frame. 
- The number of times a code occurred was counted and relationships amongst codes were analysed by noting co-occurrence and sequencing of the codes.

- Conceptual categories were created by integrating initial textual categories through fusing together a set of common codes under an overarching category to form only significant categories.

\section{- Analysis:}

- Dependability of coding was checked to ensure that coding decisions were explicit and consistent by applying the created codes to the same transcript on two occasions a week apart.

- Themes that occurred most commonly were explored in-depth through the use of the following method of generating meaning: patterns and themes were noted, themes were counted to show whether a theme was common or rare, a reasonable story was extracted from the data that could be related to the literature review, differences in coping related to police units were looked at and confirming and disconfirming evidence was examined.

\section{Strategies to ensure quality data}

Clear research questions and the plan for data collection and analysis were set out before the study commenced. A pilot study was conducted to ensure the relevance of the interview questions. The assistant who helped with data transcription was also well trained to minimise omission and loss of data.

\section{Ethical considerations}

Lists of police officers who met the set criteria for inclusion in the study were provided by the station commissioners. The primary researcher informed the participants of the purposes and procedures of the study, after which individual consent letters were signed as proof of the officers' willingness to participate in the study (Seale, Gobo, Gubrium \& Silverman, 2004).

Confidentiality was ensured by deleting data that were recorded on a voice recorder immediately after data transcription. This was done to prevent the data from being accessed by unauthorised persons, that is, anyone other than the primary researcher and the assistant who helped with transcription. Participants were referred to by their position at work and gender rather than by name, thus ensuring anonymity (Seale et al., 2004).

The participants were protected from any potential harm and were not forced to talk about issues that they found too sensitive to disclose (Seale et al., 2004). They also benefitted from the study (Landes, 2005) by receiving pamphlets on coping strategies that could be used to handle trauma, which were designed by a clinical psychologist.

\section{Trustworthiness}

The follow-up telephone interviews for checking data for representativeness were used to ensure the credibility and confirmability of data through the technique of member checking (Leedy, 1997). The use of various data collection methods and triangulation further ensured the credibility and confirmability of data (Yardley \& Marks, 2004). This also ensured that the findings could be based on a large corpus of descriptive data, further leading to the transferability of the findings. The assessment of the promoters of the primary researcher's thesis, from which this study was extracted, was used as a confirmability technique and for multiple coding to ensure inter-rater agreement and dependability (Bryman, 2008).

\section{Findings}

The SAPS officers included in this study adopt several inner coping strategies that help them to handle the effects of their operational work. Table 1 is a contingency table that presents 13 categories and subcategories of these strategies and the number of times the strategies were mentioned by the officers.

\section{Situational tolerance}

Operational work acceptance and perseverance: Some of the officers show operational work acceptance, which entails enduring traumatic scenes encountered as part of the work and being hopeful about getting out of the scenes in the future. They seem to feel obligated to do the work. Other

TABLE 1: Contingency table of inner strategies of coping with operational work amongst South African Police Service officers.

\begin{tabular}{lll}
\hline Category & Subcategories & Number of times mentioned \\
\hline Situational tolerance & Operational work acceptance; operational work perseverance; court outcome acceptance & 18 \\
Sense of responsibility & Police sense of duty; victim help & 15 \\
Spiritual mechanisms & Church attendance; individual prayer; supportive prayer & 14 \\
Case experiential learning & Advanced operational work experience; learning from case experience; transformed investigation \\
Vigilance & $\begin{array}{l}\text { Operational work experience preparedness; mixed operational work experience preparedness-avoidance; } \\
\text { operational work alertness }\end{array}$ & 9 \\
Self-nurturing & Rest; play & 9 \\
Inspiration & Self-motivation; self-encouragement; work-related optimism & 8 \\
Emotion expression & Self-directed humour; situation-directed humour; crying \\
Personal development & Media; academic study & 7 \\
Operational work interest & Police unit interest & 7 \\
Situational management & Traumatic situational control \\
Emotional regulation & Emotional restraint & 4 \\
Case management & Case separation & 2 \\
\hline
\end{tabular}


officers, however, believe that they are trapped in the work and thus have no choice but to do it. This influences them to persevere in the job rather than to accept it. Nevertheless, both strategies involve confronting the situations at work. They are also beneficial because by accepting or persevering in those situations, the officers shield themselves from further mental and emotional distress that may emanate from reminiscing about the situations. This also prevents them from viewing the operational work as difficult and enables them to continue doing the work: 'If you do not accept such things then you will have a problem and find work difficult to do' (Social crime prevention inspector, male, 46 years).

Court outcome acceptance: This is a way of controlling the officers' thoughts pertaining to unfair legal decisions in court that do not favour victims. The officers admit defeat, as they believe that there is nothing that they can do to change the decisions made. They resort to self-encouragement rather than displaying retaliatory behaviour. This encouragement makes acceptance and protection from emotional distress possible:

'This is painful but ... the magistrate makes a ruling on the basis of the investigations made, he/she depends on the nature of the evidence brought before him/her in order to make a ruling. We accept this.' (Field training sergeant, female, 32 years)

\section{Sense of responsibility}

Police sense of duty: The officers display police sense of duty by understanding their role, as law enforcement officers, responsible for curbing crimes and showing accountability to different people and institutions. Accountability in the field of policing means doing the work to meet work expectations: helping victims to have access to the required help, helping community members who believe that they depend solely on the officers for help in traumatic situations, gathering valid evidence on cases to present in court and ensuring that the cases are won in court, thus confirming their competence in their work. This helps to give meaning to their work, allowing them to maintain the mental strength to do the work and relieving them of mental distress. By preventing further victimisation of the victims, they also protect themselves from exposure to traumatic cases:

'This is because I am serving the community. The community puts all its trust in us. If you are unable to accept the situation then you start to betray the trust that the community has in you as a police officer.' (Detective captain, male, 42 years)

Victim help: Victim help means focusing on not giving up on helping the traumatised victims, but on maintaining the mental strength to assist them. Personal resources such as money and cellphones are used to assist the victims. This strategy is applicable in cases that arouse feelings of sympathy in the officers. They feel that they have to do something about the victims' situations and do so with vigour, regardless of being prohibited to do so by police procedures. Management of the victims' distress leads to the resolution of distress in the officers:

'I have worked on a case that involved the economic abuse of a child whereby the parent did not provide for him. He was dirty and had nothing. ... I found this case difficult. I felt tempted and even used personal resources to assist the child. I also felt like adopting him as he was a defenceless child.' (Social crime prevention inspector, male, 46 years)

\section{Spiritual mechanisms}

Church attendance: Officers may go to church on a regular basis or on Sundays only, especially when traumatic experiences take place on a Friday. Church attendance entails listening to sermons, singing spiritual songs, listening to other church members' testimonies of God's intervention in their lives and sharing operational experiences with pastors. The benefits of going to church include open disclosure of trauma reactions in a non-judgemental environment, strengthening oneself spiritually, understanding traumatic situations in a spiritual context and nurturing self-sufficiency by personally solving traumatic experiences before external help, like debriefing, is provided:

'Sometimes when I have experienced such situations on a Friday I go to church on Sunday. ... I could be helped by the message that is preached.... When this happens, I realise that in all things, there is nothing impossible with God.' (FCS/domestic violence inspector, male, 49 years)

Individual prayer: The officers also take time to pray individually when handling traumatic cases. This strategy involves communication with God about their views regarding those cases as well as confession of total dependence on God. This form of prayer is used as the highest form of asserting their policing responsibility as they declare this responsibility to God. Prayer is mainly used to temporarily escape the effects of victim contact, both physically and spiritually. The officers also gain the mental strength to continue working, emotional relief in the form of achieving a state of tranquillity, as well as spiritual healing and spiritual assurance that God is in charge of all the situations in their lives. This strategy also results in sustained sense of duty:

'Telling God that he is great and that I put all things in His hands as He is the One who knows all things. When I come back after being away from the victim for some time, I feel that my mind is strengthened and I am calm. ... It makes me to feel happy to know that God is the One who knows and masters these things.' (FCS/domestic violence inspector, female, 43 years)

Supportive prayer: Supportive prayer entails supporting the suspects of crimes who seem to be affected by the crimes committed. The officers support the suspects with prayer and by boosting their faith in God by assuring them that their situations will be resolved. Whilst this keeps the suspects' emotional states under control, it also benefits the officers with the resolution of their distress:

'I requested him to close his eyes so that we could pray. I told him that we could not do anything on our own but believed that God could help us in resolving the situation that we were in.' (Social crime prevention constable, female, 38 years)

\section{Case experiential learning}

Advanced operational work experience: The main objective of this strategy is to be well informed about and gain more 
years of experience in working on traumatic cases. This strategy helps with the following: regular exposure to cases, which reduces distress, having a positive attitude towards learning about cases, practical application of lessons learned, dissociating aspects of work and personal lives, operational work adaptation by changing behaviour when required to by circumstances, as well as maintaining interest in and acceptance of the operational work:

'I am used to seeing them and they are no longer as frightening as before. ... Working in the first year was problematic due to seeing dead bodies for the first time. ... However, I have now accepted the situations. ... I no longer have a problem as it is long I have been working. Ten years!' (Detective inspector, male, 45 years)

Transformed investigation: Changing the strategy used to investigate cases also helps the officers to learn the significance of their availability at the scenes of crime, particularly in domestic violence cases, in order to have first-hand knowledge of occurrences and apply relevant intervention strategies. This results in bridging the gaps in the skills required by the officers to handle the cases properly: 'I can then tell that I should be at the scene in order to handle the situation properly' (FCS/domestic violence inspector, male, 50 years).

Learning from case experience: This strategy creates an opportunity for the officers to learn valuable lessons about life and hence maintain interest in the operational work. The lessons include family and marital issues that are observed in cases such as domestic violence. The officers apply learned knowledge in handling similar cases and preventing certain unpleasant situations in their own lives:

'My line of work teaches me some things. When I see a problem such as domestic violence occurring in a particular home, I learn that what a particular person has done is wrong. I am able to apply these even at home.' (Crime prevention constable, male, 27 years)

\section{Vigilance}

Operational work experience preparedness: Four factors determine the use of this strategy: continuously changing situations at work, an encounter of different traumatic cases in one day, operational work that cannot be planned in advance, and the officers' sense of duty. The strategy entails preparation to face any type of situation that can arise, tolerating the situations that are regarded as naturally unacceptable and not depending on encouragement from other people, in and outside work, to do the operational work. Whilst this enables the officers to help the victims, it also helps the officers not to avoid the operational work but rather to confront it:

'When I leave home I come to work prepared to come across any type of situation. I might be faced with a difficult or easy situation. ... You must have perseverance as a police officer and be prepared to face any kind of situation.' (Crime prevention constable, male, 27 years)

Mixed operational work experience preparednessavoidance: Other officers exercise vigilance in the form of mixing preparedness with avoidance. This involves an approach-avoidance stance because the officers prepare themselves for different types of experiences relating to operational work. However, when the actual situations take place, the officers resort to perceptual numbing, that is, they dissociate their senses of sight or smell from the traumatic scenes, depending on the nature of the scenes. They thus shield themselves from being aware of certain aspects in traumatic scenes. This strategy counteracts the effects of the traumatic scenes and changes the atmosphere of their days at work as they show that they end up having 'good days'. This way, task accomplishment is possible:

'In order for me to continue working, I sometimes tell my mind that I am at work and am prepared to come across anything. Having experienced these, I ignore them as though I have not seen anything because we experience a lot of different situations.' (Field training sergeant, female, 32 years)

Operational work alertness: This strategy entails being alert when doing operational work and familiarising oneself with police investigation procedures and methods used by perpetrators to commit crimes. This ensures the success of case investigations. These tasks require the following characteristics from the officers: being mentally strong to handle cases, introducing new tactics to investigate cases, working hard, having a fearless approach to cases, conducting investigations in every setting in the the victims' lives, and not undermining the seriousness of the cases handled. Its outcomes are that the officers are able to gather as much evidence on the cases as possible and it redirects the officers' perception of cases: 'You must be very alert and be very strong in order to do this work' (Detective inspector, male, 46 years).

\section{Self-nurturing}

Rest: Being in a state of rest creates a conducive atmosphere for the officers to use other inner strategies effectively. For instance, it involves listening to softly played music and reading books, including spiritual books. An environment of rest creates an arena that is suitable for harnessing the benefits of these strategies as it creates a quiet environment. It helps with temporary disengagement from cases in order to regain the mental strength to handle them effectively later, recovering from the distress that is experienced, forgetting traumatic experiences, and contextualisation of traumatic situations:

'I try to find a quiet place everyday when I reach home where I can rest. ... If I am playing the radio then it must be playing softly. In that way, I feel that I regain strength.' (FCS inspector, male, 49 years)

Play: Play refers to the combination of pleasant and relaxing activities to get over experienced distress. These activities include watching pleasant television programmes that do not remind the officers of the operational experiences encountered at work, alternating between watching television and reading books, playing sports and exercising. These activities help them to not spend time alone, prevent preoccupation with thoughts about scenes, redirect negative 
thoughts about work and life in general, prevent destructive behaviour, as well as separate family and work-related matters:

'I should find something to play with. It could be deriving pleasure from watching television. ... However, I should not watch things that are similar to what I was involved in. ... They make me to focus on things that are shown there. This makes me a good man.' (Detective inspector, male, 47 years)

\section{Inspiration}

Self-encouragement and self-motivation: Whilst the operational work done is interpreted as distressing, the officers also get inspiration from it to ensure that perpetrators face the consequences of their actions. They encourage themselves to focus on achieving this goal. The perceived goal outweighs the distress encountered. Self-encouragement is accompanied by self-motivation, that is, the enthusiasm to achieve the goal set. Whilst self-encouragement boosts their confidence in achieving the goal, self-motivation gives an impetus to the process of achieving the goal and decreases the distress experienced: 'Those things give me more motivation that I must stand up everyday. This is driven by my willingness to stop the abuse' (FCS/domestic violence constable, female, 30 years).

Work-related optimism: The officers alsogain encouragement to continue doing the work by hoping that the state will ultimately improve their operational functioning and by acknowledging its effects on the officers' mental health:

'Another way is that I have hope that as we are working the state will realise that ... perhaps there could be changes in the way that we work as we are continuously exposed to these things.' (Detective inspector, male, 45 years)

\section{Emotion expression}

Self-directed humour: This strategy entails turning the experiences encountered at work into a funny story and laughing at oneself. By adopting this stance, the effects of the operational experiences do not distress the officers at the end:

'I forget most of the things. ... I am telling you that I will get into a shop, move around the shop, start calling home to indicate that I have forgotten what I was supposed to bring back home. ... Then I will start to laugh at myself that "Hey! This is bad; really bad!"' (FCS/domestic violence superintendent, male, 55 years)

Situation-directed humour: Laughter is also directed at the operational situations themselves. By turning the situations into a joke, the officers ensure that the situations do not affect them, specifically their emotions, and that they are able to continue doing the work. The use of this strategy is a result of having a simple approach to life:

'I am a kind of person who likes to laugh. I laugh about things in order not to be affected by them. ... Laughing helps me to control my emotions.' (Social crime prevention inspector, male, 46 years)

Crying: Police officers may also be so overwhelmed by the encountered situations that they may choose to cry. The expression of negative emotions helps them to relieve the pressure caused by the cases and to continue with their work:
'What I usually do when I am faced with a painful situation is that I excuse myself for a short period of time, go to the toilet and cry until I feel that I am strong enough to go back to face the people.' (Social crime prevention constable, female, 38 years)

\section{Personal development}

Media: The officers develop their confidence in handling cases by reading books, newspapers and magazines that talk about specific cases as well as by watching police-related television programmes, specifically $P O L T V$, which helps with learning more about the nature of different cases and how to handle them: 'Other ways include watching POL TV. We watch it every Wednesday. We see a lot of scenes on $\mathrm{TV}$, including murder. It helps in learning more about cases' (Detective inspector, male, 47 years).

Academic study: Personal development also involves studying towards specific academic qualifications. This helps officers to develop their academic knowledge of police roles so they can do their work excellently. It keeps them busy so they do not become preoccupied with the traumatic cases they are exposed to and helps to prevent destructive behaviour. They can also use the knowledge gained for selfreflection:

'I have noticed that a way out of this is to enroll and continue reading books. ... It helps me not to wander around or just find myself angry at people ... and forget about work-related matters. ... These books reflect who I am.' (Detective inspector, male, 47 years)

\section{Operational work interest}

Police unit interest: This strategy entails being attracted to and having a desire to do the operational work, and being affectionate about it. It benefits the officers as they continue to be interested in doing the work, increase their knowledge and experience about the work, face the challenges that come with the work, and are less affected by the cases handled: 'To me it was because I had interest in working in this unit. Maybe that is the reason I did not experience any problem' (Detective inspector, male, 45 years).

\section{Situational management}

Traumatic situational control: This strategy is primarily aimed at protecting all the people involved in a crime scene (victims, perpetrators, onlookers) from further harm. The officers also use it to protect themselves from distress that may result from the potential further victimisation: 'I must start by controlling the situation.... They started to fight with those people thinking of competing with cars, which could cause another accident' (Social crime prevention constable, male, 27 years)

\section{Emotional regulation}

Emotional restraint: This strategy entails redirecting one's thoughts when in a traumatic scene in order to curb negative emotions, taking the victims' situations into consideration, 
and taking into account one's position as a police officer and one's police sense of duty. All these considerations and forms of self-control not only benefit the officers by inhibiting negative talk and preventing their victimisation but also prevent perpetuating the negative situations, thus protecting everyone involved in the scenes:

'If you do not control your emotions then you can end up saying things that may influence those people to pay revenge somehow to a point of burning the perpetrator's house or search for him and kill him.' (Detective inspector, male, 46 years)

\section{Case management}

Case separation: This entails treating each case separately and on the basis of its importance. The officers do not try to carry over the effects of one case to another. In this way, the officers prevent the accumulation and mismanagement of trauma reactions, which may affect their work. Each case is also attended to properly:

'I also live by a certain principle: I do not associate cases but handle them individually on the basis of what is required. By so doing, I do not allow one case to influence the way I should handle another case.' (Social crime prevention inspector, male, 46 years)

\section{Discussion}

\section{Outline of the results}

The study shows, as suggested by Rothmann et al. (2011) that problem-focused coping forms the major component of managing stressful and traumatic experiences during operational work. These forms include sense of responsibility, case experiential learning and vigilance. Nevertheless, emotion-focused coping in the form of situational tolerance appears to be relied upon most commonly by officers above all the other types of strategies. Case management, though a problem-focused coping strategy, is the least used. The use of spiritual mechanisms, a reappraisal strategy, is also a commonly adopted strategy for this management.

In addition, these inner strategies of coping may, in some situations, be used independently of one another. However, in other situations, depending on the complexity of the situations (Cronqvist, Klang \& Bjorvell, 1997), problemfocused and emotion-focused strategies may be combined. Types of problem-focused strategies, such as sense of responsibility, case experiential learning and operational work interest, may be used jointly. Problem-focused strategies like sense of responsibility and the reappraisal strategy of spiritual mechanisms also go together. A combination of problem-focused and avoidance strategies (mixing preparedness and avoidance) is also shown in this study. All these combinations ensure officers' management of the impact of their work.

Whilst the same types of strategies may be used amongst police officers, their purpose may differ. For instance, Rothmann et al. (2011) found that the combination of problem-focused coping with ventilation of emotions led to work disengagement amongst police officers in a study on work engagement. Ventilation of emotions was an avoidance strategy in Rothmann et al.'s (2011) study whilst in the current study as in Carver, Scheier and Weintraub's study (cited in Rothmann et al., 2011), this means the release of emotional pressure, which leads to effective management of the impact of the work. This emotional release helps the officers to face the encountered situations; thus this is not an avoidance strategy but an approach strategy. Beasley et al. (2003) confirm that this strategy can take two forms: expression of emotions, which reflects its approach aspect, and sealing over of emotions that are experienced, serving an avoidance purpose.

Emotional restraint leads to the regulation of negative emotions in order to ensure involvement in traumatic scenes and helping victims involved in the scenes. This shows its positive outcome. Similarly, Van Gederen, Konjin, and Bakker (2011) cite deep acting, the control of inner thoughts and feelings amongst police officers, as an emotional regulation strategy that ensures calmness and control and thus allows officers to meet goals at work and ensure client satisfaction.

This study also shows that it is not only the degree of use of avoidance and emotion expression strategies that should be considered in the management of the impact of operational work, but also the dimensions of the strategies as well. For instance, the minimal use of perceptual numbing and low expression of negative emotions, accompanied by involvement in the operational situations, leads to engagement in the work. This is dependent on the nature of the operational situations encountered. This helps the officers to avoid distressing aspects of the operational work but to get the work done at the end. The combination of high problemfocused, low avoidance and low ventilation of emotions confirms findings in a sample of nurses in Rothmann et al.'s (2011) study.

A further two outcomes are noted: firstly, there is resilience to traumatic operational situations. Beasley et al. (2003) define resilience to stressful situations on the basis of four criteria: (1) cognitive hardiness, which is shown by the officers in this study through their sense of responsibility and carrying out of their duties regardless of the critical incidents encountered, (2) managing to go through several stressful situations and dealing with them, (3) being strengthened mentally and spiritually by those situations rather than merely being made aware of them, and (4) development of useful coping strategies for improved ways of handling the situations whilst engaging in them.

Secondly, these inner coping strategies serve as job resources that moderate the demands of the operational work and may contribute to the officers' engagement at work. The three dimensions used to define work engagement in literature may be signified by the outcomes of the following coping strategies in this study: (1) dedication to work (police sense of duty, interest in the operational work, maintaining hope, selfencouragement and motivation, experience gained, personal 
development to handle cases and changing investigation strategies as need arises), (2) vigour (preparedness and alertness in handling operational situations, handling cases according to degree of importance and control of difficult situations) and (3) absorption (helping victims) (Rothmann et al., 2011; Storm \& Rothmann, 2003). These outcomes further ensure the officers' efficiency at work.

\section{Practical implications}

This study contributes to the body of knowledge on dimensions of inner coping strategies amongst SAPS officers with special reference to operational work in the Vhembe district (South Africa). This calls for intervention programmes designed for the SAPS, including critical incident stress debriefing (CISD), to take the operational officers' inner strategies into account in order to improve their effective management of the impact of their work.

\section{Limitations of the study}

The sample size of 20 could have been increased to gather more dense and contextual data. There was also only one participant who represented the field training police unit. Therefore, the perceptions of officers in this unit were not well represented. Credibility and confirmability could have been better ensured through face-to-face contact with participants and gathering sincere answers during member checking rather than relying on telephonic conversations.

\section{Conclusion}

This study uncovered setting-specific inner coping strategies amongst SAPS officers in the Vhembe district relating to operational work. Further research is, nevertheless, required to evaluate these strategies. It is recommended that the SAPS should encourage operational work officers to develop adaptive inner coping strategies to use for self-care to ensure that they are not overcome by critical incidents during their work but are able to thrive and contribute meaningfully towards the assistance of victims of trauma. The training of professionals who provide CISD to officers should also incorporate two components: (1) exploring these inner strategies in the individual officers that they assist and (2) developing focused effort recovery methods to cope with adverse circumstances that can be instilled in the officers.

Future research should focus on conducting quantitative studies in other, similar settings of the SAPS, with bigger samples and more carefully balanced characteristics of participants, including religious affiliations, in order to address the shortcomings of the current study. Future research should also determine how training of police recruits can incorporate a component of exploring inner coping strategies when faced with traumatic incidents in order to assess the recruits' degree of resilience.

The objective of this study was to describe inner strategies used in the operational work context of SAPS officers in the Vhembe district to manage the impact of stressful and traumatic situations. The results show that the main categories of inner coping strategies that lead to management of stress and trauma amongst the selected sample are centred around problem-focused and emotion-focused strategies with some use of reappraisal and minimal use of avoidance. Considering the context of the officers' work, the list of inner coping strategies amongst SAPS officers to manage the impact of stressful and traumatic situations at work should be extended.

\section{Acknowledgements}

This article was extracted from a doctoral thesis for the University of South Africa, supported by a grant from the University of Venda Research and Publications Committee: 'A grounded theory of police critical incidents impact management amongst SAPS officers in the Vhembe district, Limpopo province'.

\section{Competing interests}

The authors declare that they have no financial or personal relationship(s) that may have inappropriately influenced them in writing this article.

\section{Authors' contributions}

M.A.G. (University of Venda and University of South Africa) was the primary researcher whilst M.E.F. (University of South Africa) and M.J.T.B. (University of South Africa) were the primary researcher's supervisors who contributed as critical readers and co-authors in the development of the text.

\section{References}

Bakker, A.B., \& Daniels, K. (2012). A day in the life of a happy worker: Introduction. In A.B. Bakker, \& K. Daniels (Eds.), A day in the life of a happy worker. Hove, Sussex, UK: Psychology Press.

Bakker, A. B., \& Demerouti, E. (2006). The job demands-resources model: State of the art. Journal of Managerial Psychology, 22(3), 309-328. http://dx.doi. org/10.1108/02683940710733115

Barbour, R.S. (2001). Checklists for improving rigour in qualitative research: A case of the tail wagging the dog? British Medical Journal, 322, 1115-1117. http://dx.doi. org/10.1136/bmj.322.7294.1115, PMid:11337448

Beasley, M., Thompson, T., \& Davidson, J. (2003). Resilience in response to life stress: The effects of coping style and cognitive hardiness. Personality and Individual Differences, 34(1), 77-95. http://dx.doi.org/10.1016/S0191-8869(02)00027-2

Bekwa, N., \& De Beer, M. (2009). Salutogenic profile of police trainees on entry into the profession. Journal of Psychology in Africa, 19(2), 177-186.

Bell, H., Kulkarni, S., \& Dalton, L. (2003). Organizational prevention of vicarious trauma. Families in Society: The Journal of Contemporary Human Services, 84(4), 463-470. http://dx.doi.org/10.1606/1044-3894.131

Bryman, A. (2008). Social research methods. New York, NY: Oxford University Press. http://dx.doi.org/10.1557/PROC-1123-1123-P03-08, http://dx.doi.org/10. 1080/13645570701401644

Cronqvist, A., Klang, B., \& Bjorvell, H. (1997). The use and efficacy of coping strategies and coping styles in a Swedish sample. Quality of Life Research, 6(1), 87-96. $\mathrm{http} / / / \mathrm{dx}$.doi.org/10.1023/A:1026425730325, PMid:9062446

De Jonge, J., Dollard, M.F., Dormann, C., Le Blanc, M., \& Houtman, I.L.D. (2000). The demand-control model: Specific demands, specific control, and well-defined groups. International Journal of Stress Management, 7(4), 269-287. http://dx.doi. org/10.1023/A:1009541929536

Department of Cooperative Governance and Traditional Affairs. (2011). Vhembe District Municipality Profile. Retrieved July 17, 2013, from www.nda.agric.za/.../ profiles\%202011\%20vhembe\%20aug.docx

Franchuk, J.E. (2004). Phenomenology vs grounded theory: The appropriate approach to use to study the perspectives of instructional librarians on their roles in information literacy education for undergraduates. Paper written for Interdisciplinary Studies 560, Qualitative Methods. Retrieved October 10, 2005, from http://www.slis.ualberta.ca/cap04/judy/paper.htm 
Hobfoll, S.E., Dunahoo, C.A., \& Monnier, J. (1995). Conservation of resources and traumatic stress. In J.R. Freedy, \& S.E. Hobfoll (Eds.), Traumatic stress: From theory
to practice (pp. 29-47). New York, NY: Plenum. http://dx.doi.org/10.1007/978-1to practice ( $\mathrm{pp}$.

Joffe, H., \& Yardley, L. (2004). Content and thematic analysis. In D.F. Marks, \& L. Yardley (Eds.), Research methods for clinical and health psychology (pp. 56-68). New Delhi, India: Sage Publications.

Jonas, N.M. (2003). The impact of trauma debriefing on debriefers in the context of the South African Police Service helping professions, Limpopo province. Unpublished master's dissertation, University of Pretoria, Pretoria, South Africa.

Kgalema, L. (2002). Victim awareness and trauma management in metropolitan police services. (Research report). Centre for the Study of Violence and Reconciliation. Retrieved April 29, 2006, from http://www.wits.ac.za/csvr/papers/papkgal2.htm

Landes, M. (2005). Can context justify an ethical double standard in clinical research in developing countries? Globalization and Health, 1(11), 5 pages. http://dx.doi. org/10.1186/1744-8603-1-11

Latack, J.C., \& Havlovic, S.J. (1992). Coping with job stress: A conceptual evaluation framework for coping measures. Journal of Organisational Behavior, 13(5), 479 508. http://dx.doi.org/10.1002/job.4030130505

Leedy, P.D. (1997). Practical research: Planning and design. Ohio: Merrill, an Imprint of Prentice Hall.

Louw, G. J., \& Viviers, A. (2010). An evaluation of a psychosocial stress and coping model in the police work context. South African Journal of Industrial Psychology, 36(1), 11 pages. http://dx.doi.org/10.4102/sajip.v36i1.442

Madu, S.N., \& Poodhun, S.E.A. (2006). Stress symptoms and substance use among police officials in the central region of Limpopo province, South Africa. Journal of Social Science, 12(3), 213-224.

Minnaar, A., \& Mistry, D. (2006). Dealing with the use of force and stress-related violence by members of the police: Some observations from selected case studies in Gauteng province, South Africa. Acta Criminologica, 19(3), 29-63.

Neuman, W.L. (2007). Basics of social research: Qualitative and quantitative approaches. Sydney, Australia: Pearson Education.
Pienaar, J., \& Rothmann, S. (2003). Coping strategies in the South African Police Service. South African Journal of Industrial Psychology, 29(4), 81-90. http:// dx.doi.org/10.1177/0093854806288708

Pienaar, J., Rothmann, S., \& Van de Vijver, F.J.R. (2007). Occupational stress, personality traits, coping strategies and suicide ideation in the South African Police Service. Criminal Justice and Behaviour, 34(2), 246-258.

Rani, R., \& Kumar, N. (2012). Quality of work life: Predictor of psychological wellbeing of police employees. Indian Journal of Positive Psychology, 3(4), 356-364.

Rothmann, S., Jorgensen, L.I., \& Hill, C. (2011). Coping and work engagement in selected South African organisations. South African Journal of Industria Psychology, 37(1), 11 pages. http://dx.doi.org/10.4102/sajip.v37i1.962

Seale, C., Gobo, G., Gubrium, J.F., \& Silverman, D. (2004). Qualitative research practice London, UK: SAGE Publications. http://dx.doi.org/10.4135/9781848608191.d32

Storm, K., \& Rothmann, S. (2003, May). Burnout in the South African Police Service. Poster presented at the 11th European Congress of Work and Organisational Psychology, Lisbon, Portugal.

Strauss, A, \& Corbin, J. (1998). Basics of qualitative research: Techniques and procedures for developing grounded theory. New Delhi, India: SAGE Publications.

Van Gederen, B.R., Konjin, E.A., \& Bakker, A.B. (2011). Emotional labor among trainee police officers: The interpersonal role of positive emotions. Journal of Positive Psychology, 6(2), 163-172. http://dx.doi.org/10.1080/17439760.2011.558849

Waters, J.A., \& Ussery, W. (2007). Police stress: History, contributing factors, symptoms and interventions. Policing: An International Journal of Police Strategies an

Wright, R., Powell, M.B., \& Ridge, D. (2006). Child abuse investigation: An in-depth analysis of how police officers perceive and cope with daily work challenges.
Policing: An International Journal of Police Strategies and Management, 29(3), 498-512. http://dx.doi.org/10.1108/13639510610684728

Yardley, L, \& Marks, D.F. (2004). Introduction to research methods in clinical and health psychology. In D.F. Marks, \& L. Yardley (Eds.), Research methods for clinical and health psychology (pp. 1-20). New Delhi, India: Sage Publications. 